\title{
Factors Influencing Students' Performance in a Brazilian Dental School
}

\author{
Erica Tatiane da SILVA \\ Maria de Fátima NUNES \\ Maria Goretti QUEIROZ \\ Cláudio R. LELES
}

Dental School, Federal University of Goiás, Goiânia, GO, Brazil

\begin{abstract}
Comprehensive assessment of students' academic performance plays an important role in educational planning. The aim of this study was to investigate variables that influence student's performance in a retrospective sample including all undergraduate students who entered in a Brazilian dental school, in a 20-year period between 1984 and 2003 ( $\mathrm{n}=1182)$. Demographic and educational variables were used to predict performance in the overall curriculum and course groups. Cluster analysis (K-means algorithm) categorized students into groups of higher, moderate or lower performance. Clusters of overall performance showed external validity, demonstrated by Chisquare test and ANOVA. Lower performance groups had the smallest number of students in overall performance and course groups clusters, ranging from $11.8 \%$ (clinical courses) to $19.2 \%$ (basic courses). Students' performance was more satisfactory in dental and clinical courses, rather than basic and non-clinical courses $(\mathrm{p}<0.001)$. Better student's performance was predicted by lower time elapsed between completion of high school and dental school admission, female gender, better rank in admission test, class attendance rate and student workload hours in teaching, research and extension $\left(\mathrm{R}^{2}=0.491\right)$. Findings give evidence about predictors of undergraduate students' performance and reinforce the need for curricular reformulation focused on with improvement of integration among courses.
\end{abstract}

Key Words: dental education, dental students, curriculum, cluster analysis.

\section{INTRODUCTION}

Recent efforts at a global level have focused on the discussion of professional competencies and quality standards in dental education $(1,2)$. Despite the differences in worldwide educational systems, there are convergent views toward curriculum reformulation and improvement of the knowledge of learning process in dental education.

An ideal dental educational environment should enable students to acquire non-clinical, clinical and interpersonal competencies, which must be supported by integration among knowledge of biomedical, behavioral, and dental courses, by cognitive and psychomotor skills, and by professional and ethical values $(1,2)$. However, process of planning, implementation and sustaining of these deep innovations is complex and dynamic (3). Consequently, there has been increasing interest in researching factors to maximize success of educational experience for each student and outcome of undergraduate program.

Studies describing the educational experience of dental students traditionally have focused on characteristics of the learner, academic environment and curriculum structure (3-7). Few reports regarding student's performance in dental school are found in international literature (8-10). They were mainly crosssectional studies conducted in a small sample, and that analyzed relation between school admission criteria and isolated measures of dental school achievement as student performance in basic or preclinical courses and scores on National Board Dental Examination (NBDE). Moreover, most studies about student's performance have been conducted in either North America or Europe, and their applicability to Latin American students is largely unknown, considering the differences between higher education systems and curricula.

Additional studies are essential to elucidate trends 
and predictors for successful academic performance, plan and evaluate organizational development and curriculum structure, as well as develop priority goals for research in dental education, especially in Latin America. Thus, the aim of this study was to investigate the variables that influence undergraduate student's performance in a Brazilian dental school.

\section{MATERIAL AND METHODS}

A retrospective cross-sectional study was designed including all students who entered the Dental School of the Federal University of Goiás, State of Goiás, Brazil, between 1984 and 2003. This public dental school has a 5-year curriculum and offers 60 places to new incoming students annually. In the first 2 years of the graduation course predominantly basic and non-clinical courses are offered, while in the subsequent years students have dental and clinical courses. Earlier classes (before 1984) were not included in the study because they had a different curriculum design. After approval of the research protocol by local Institutional Review Board, demographic features, preadmission credentials, and academic data were retrieved by the University Registrar's Office.

Brazilian universities accept students directly from high school. Candidates for university must pass an admission test that includes issues of all disciplines of high-school education. This exam was used by universities to select candidates out of an extremely competitive applicant pool since 1910. Admission to public universities is a very hard process due to the high proportion of applicants per place, because these universities are funded by the Federal or State governments and are the most renowned in Brazil. School admission depends on the student's rank in the admission test, considering a limited number of places.

Retrieved data for this study included type of high school (private or public), elapsed time between completion of high school and dental school admission, and rank of candidate's performance the in admission test. Academic data comprised student's academic performance, time to degree, rate of class attendance and student workload hours in teaching, research and extension activities.

In this study, student's performance in each course was measured as the mean value of 4 bimonthly examinations, rated quantitatively in a $0-10$ scale. Outcome variable was overall student's performance within the undergraduate program. In Brazil, performance of dental students is provided by the cumulative grade point average, and there is no examination for licensure to practice dentistry, as the National Board Dental Examination. Student's performance in course groups was also measured for basic and dental, and non-clinical and clinical courses. The term 'basic courses' refers to biomedical and behavioral sciences, i.e. non-dental courses, while 'non-clinical courses' represents those that don't involve clinical practice, including dental courses.

The whole sample was segmented into a predefined number of clusters according to student's performance measures. The pattern of student's performance was defined by cluster analysis with the K-means algorithm. Cluster analysis aims to identify natural groupings of data from a large data-set to produce a concise representation of a system's behavior. This statistical tool partitions subjects into different groups on the basis of a minimal within-group and a maximal between-group variation, without prejudgment. The algorithm in K-means cluster analysis requires a priori definition of the number of clusters. The K-means algorithm assigns each point to the cluster whose center (also called centroid) is nearest. The center is the average of all the points in the cluster, that is, its coordinates are the arithmetic mean for each dimension separately over all the points in the cluster.

Classification procedure was performed based on overall student's performance and by course groups, so that students categorized into a 3-cluster solution: higher, moderate, or lower performance. Statistical differences among clusters were investigated using chi-square test and one-way ANOVA followed by Tukey's post hoc for nominal and continuous independent variables, respectively. Paired-samples t test was used to compare student performance by different course groups.

Stepwise multiple regression analysis was used to test the influence of independent variables on the overall student's performance. Significance level was set at $p<0.05$. SPSS 16.0 for Windows was used for statistical analysis.

\section{RESULTS}

Study population included 1182 students, $63.1 \%$ females. Mean age was 19.54 years $(\mathrm{SD}=2.05)$ at the time of dental school admission and 23.54 years $(\mathrm{SD}=2.07)$ 
at the time of graduate degree.

Table 1 includes descriptive analysis and comparison among clusters of overall student's performance. Only the variables type of high school and rank in dental school admission test were not statistically different among the clusters.

Taking into account the large data-set used in this research, cluster analysis was used to identify satisfactorily 3 groups of students with differing patterns of overall student's performance (lower, moderate or higher) and external validation, as demonstrated by the bivariate analysis. Lower performance cluster $(n=195 ; 16.5 \%)$ was characterized predominantly by males and older students, with higher elapsed time from completion of high school until dental school admission, as well lowest rate of class attendance, lowest student workload hours and higher time to graduate degree. Higher performance cluster $(\mathrm{n}=456 ; 38.6 \%)$ presents opposite patterns to the lower performance group. Moderate performance cluster was the most prevalent $(\mathrm{n}=531 ; 44.9 \%)$, with intermediary academic measures.

The analysis of student's performance by course groups (Table 2) revealed that the segments of lower performance comprised the smallest number of students, ranging from 11.8 (clinical courses) to $19.2 \%$ (basic courses). There were differences in student performance between the course groups $(\mathrm{p}<0.001)$, with higher scores in dental and clinical courses. Table 3 shows student distribution according student's performance by course groups.

Stepwise multiple regression analysis (Table 4) of the influence of independent variables on overall student's performance resulted in $\mathrm{R}^{2}$ value that indicates that the final model accounts for $49 \%$ of the variance in outcome variable.

\section{DISCUSSION}

The effectiveness of educational principles and curriculum structure becomes known when student performance is systematically assessed. This study focused on identification of variables that influence student's performance in a 5-year program of a public dental school, using a large student sample and its associated demographic features, preadmission credentials, and academic data.

Earlier studies have examined the relationship between student's performance and some of the independent variables of Table 1, like gender $(10,11)$ and performance in the admission test $(8,9,12)$. There are no tuition or entrance fees in public universities, as imposed by the Brazilian Federal Constitution, but considering

Table 1. Clusters characteristics according to independent variables.

\begin{tabular}{|c|c|c|c|c|}
\hline Variables & $\begin{array}{l}\text { Lower performance } \\
\qquad(\mathrm{n}=195)\end{array}$ & $\begin{array}{c}\text { Moderate performance } \\
\qquad(\mathrm{n}=531)\end{array}$ & $\begin{array}{l}\text { Higher performance } \\
\qquad(\mathrm{n}=456)\end{array}$ & $\mathrm{p}$ value \\
\hline Age at admission (years) ${ }^{* *}$ & $20.48(3.4)^{\mathrm{A}}$ & $19.8(2.1)^{\mathrm{B}}$ & $19.04(1.7)^{\mathrm{C}}$ & $<0.001$ \\
\hline \multicolumn{5}{|l|}{ Gender } \\
\hline Female & 34.4 & 63.5 & 75.0 & \multirow{2}{*}{$<0.001$} \\
\hline Male & 65.6 & 36.5 & 25.0 & \\
\hline \multicolumn{5}{|l|}{ Type of high school } \\
\hline Private & 90.1 & 91.6 & 92.9 & \multirow{2}{*}{ N.S. } \\
\hline Public & 9.9 & 8.4 & 7.1 & \\
\hline $\begin{array}{l}\text { Time between end of high school } \\
\text { and dental school admission (years)* }\end{array}$ & $2.1(2.8)^{\mathrm{A}}$ & $1.6(1.7)^{\mathrm{A}}$ & $0.9(1.1)^{\mathrm{B}}$ & $<0.001$ \\
\hline Rank in admission test** & $28.7(14.4)$ & $28.1(16.2)$ & $27.31(16.1)$ & N.S. \\
\hline Time to degree (years)** & $5.10(0.5)^{\mathrm{A}}$ & $4.99(0.1)^{\mathrm{B}}$ & $4.95(0.2)^{\mathrm{B}}$ & $<0.001$ \\
\hline Rate of class attendance $(\%)^{* *}$ & $89.6(4.1)^{\mathrm{A}}$ & $92.4(2.1)^{\mathrm{B}}$ & $93.9(1.8)^{\mathrm{C}}$ & $<0.001$ \\
\hline Student workload hours** & $4351.5(223.8)^{\mathrm{A}}$ & $4413.4(311.2)^{\mathrm{B}}$ & $4570.8(444.8)^{\mathrm{C}}$ & $<0.001$ \\
\hline
\end{tabular}

* Chi-square test and one-way ANOVA followed by Tukey's post-hoc test. ** Mean (s.d.) 
universities accept only a small fraction of applicants, only well-prepared students succeed in the university entrance exam. As a consequence, most dental students of public universities come from private high schools and from middle- or upper-class families. In Brazil, the better quality of private high schools is remarkable, which explains the predominance of students from these institutions in the present study.

As well as for overall performance, segments of lower performance also showed smallest number of students among student's performance clusters by course groups (Table 2). However the significant number of students with lower performance reveals need for specific educational strategies for this segment, mainly due to the tendency of students to remain in their performance clusters in different course groups (Table 3). If dental

Table 2. Comparison of student's performance by course groups.

\begin{tabular}{|c|c|c|c|c|}
\hline & n $(\%)$ & Mean (s.d.) & CI95\% & $\mathrm{p}$ value \\
\hline \multicolumn{5}{|l|}{ Overall courses } \\
\hline High performance & $456(38.6)$ & $8.13(0.26)$ & $8.10-8.15$ & \multirow{3}{*}{---- } \\
\hline Moderate performance & $531(44.9)$ & $7.41(0.21)$ & $7.39-7.43$ & \\
\hline Low performance & $195(16.5)$ & $6.60(0.40)$ & $6.54-6.66$ & \\
\hline \multicolumn{5}{|l|}{ Basic courses } \\
\hline High performance & $466(39.7)$ & $7.95(0.41)$ & $7.91-7.98$ & \multirow{7}{*}{$<0.001$} \\
\hline Moderate performance & $482(41.1)$ & $6.85(0.32)$ & $6.82-6.88$ & \\
\hline Low performance & $225(19.2)$ & $5.63(0.54)$ & $5.55-5.69$ & \\
\hline \multicolumn{4}{|l|}{ Dental courses } & \\
\hline High performance & $501(42.4)$ & $8.18(0.24)$ & $8.15-8.20$ & \\
\hline Moderate performance & $552(46.7)$ & $7.52(0.21)$ & $7.50-7.53$ & \\
\hline Low performance & $129(10.9)$ & $6.70(0.43)$ & $6.63-6.78$ & \\
\hline \multicolumn{5}{|l|}{ Non-clinical courses } \\
\hline High performance & $474(40.1)$ & $8.12(0.32)$ & $8.09-8.15$ & \\
\hline Moderate performance & $521(44.1)$ & $7.28(0.25)$ & $7.25-7.30$ & \\
\hline Low performance & $187(15.8)$ & $6.30(0.49)$ & $6.23-6.37$ & $<0.001$ \\
\hline \multicolumn{5}{|l|}{ Clinical courses } \\
\hline High performance & $500(42.3)$ & $8.13(0.26)$ & $8.11-8.16$ & \\
\hline Moderate performance & $543(45.9)$ & $7.40(0.21)$ & $7.38-7.42$ & \\
\hline Low performance & $139(11.8)$ & $6.59(0.44)$ & $6.51-6.66$ & \\
\hline
\end{tabular}

*Paired-samples t test. educators are able to identify students at risk, they may take effective measures to prevent failure (as observed among students with lower performance in Table 1). Student's performance was more satisfactory in dental and clinical courses, rather than basic and non-clinical courses, respectively (Table 2). This finding suggests critical dichotomies in the curriculum: lack of integration between basic and clinical courses, and non-clinical and dental courses $(1,4,5,7)$.

Most dental schools are organized along traditional course boundaries (5). In the traditional 5-year Bachelor degree in Dentistry, offered for example in the Federal University of Goiás, students take courses in biomedical sciences and general education during the first 4 semesters, while the subsequent semesters focus on the clinical courses and, more directly, on clinical training.

Fugill (13) and Henzi et al. (14) investigated strengths and weaknesses of dental school curriculum, in the student's point of view. Participants have positive opinions about their learning experiences, but they also recognized several problematic areas, including lack of situating the received knowledge in a particular context (13) and identification of large issues of the curriculum as being of questionable relevance, mainly in the biomedical and behavioral sciences (14). Similar results were found in a survey commissioned by American Dental Association Survey Center (15), reinforcing the desire of students for a more well-organized curriculum and greater support for improving clinical experience.

It is gradually recognized that approaches that integrate basic and clinical courses provided a more meaningful and holistic preparation for dentistry $(1,4,16)$. Curriculum integration is essential in the preparation of the new general dentist able to solve patients' problems and incorporate new concepts and therapies into health 
care $(1,5,7)$. This involves making a markedly significant cultural and attitudinal shift in dental schools, with recognition that basic and other sciences are important to form a competent dentist in 21 st century (4). Planning and implementing of these changes represent considerable risk of financial burdens on schools, need for training programs and workshops for faculty, increased training time for students, and re-structuring licensure procedures and curriculum (4).
Findings of the present study also revealed that overall student's performance was related to elapsed time between completion of high school and dental school admission, gender, dental school admission, rank in admission test, rate of class attendance and student workload hours in teaching, research and extension (Table 4).

Student selection and recruitment are considered as vital in the successful outcome of dental education (6). Admission to graduate programs in the health professions is based on different factors, including undergraduate/pregraduate student's performance, extracurricular and research activities, interviews, and psychomotor assessments, varying the degree of emphasis placed on these factors according to the institutions $(6,8,9,12)$. In Brazil dental school admission is focused on purely academic criteria (grades achieved in university entrance examination).

Admission information has historically been used as a predictor of academic success in dental school (12). Previous studies reports relationship between admission criteria (college grade point average - GPA, subtest scores on the Dental Admission Test - DAT, interviews) and scores on the NBDE or student performance on basic

*Chi-square test.

Table 4. Stepwise multiple regression of the influence of independent variables in the overall student performance.

\begin{tabular}{lccccc}
\hline & $\beta$ & $\begin{array}{c}\text { Std } \\
\text { error }\end{array}$ & $\begin{array}{c}\text { Standardized } \\
\text { coefficients }\end{array}$ & $\begin{array}{c}\mathrm{p} \% \text { CI } \beta \\
\text { value* }\end{array}$ \\
\hline Rate of class attendance (\%) & 0.111 & 0.006 & 0.514 & $0.099-0.123$ & $<0.001$ \\
Student workload hours & 0.001 & 0.000 & 0.221 & $0.000-0.001$ & $<0.001$ \\
Time between end of high school and dental school admission (years) & -0.070 & 0.009 & -0.195 & $-0.089--0.051<0.001$ \\
Gender: Female & -0.230 & 0.033 & -0.189 & $-0.296--0.164<$ & $<0.001$ \\
Rank in admission test & -0.003 & 0.001 & -0.077 & $-0.005--0.001<<0.01$ \\
\hline
\end{tabular}

* Stepwise multiple regression. $\mathrm{R}^{2}=0.491$. 
and predental courses $(8,9,11,12)$. Undergraduate total GPA and DAT academic score have been shown to be 2 of the best predictors of dental school performance.

The present findings reinforce that admission criteria are related with student's performance during the formative years. According McManus and Richards (16), this may be attributed to the 3 arguments: achievement, ability and motivation. These authors claim that successful performance in the admission test is a reflection of the intelligence and motivation of the student, which will have a positive effect on their success in university performance. Others studies showed that admission level has limited value as a predictor of students' performance $(17,18)$.

Cognitive ability predicts a broad spectrum of important life outcomes, behaviors, and performances, including academic achievement. However it is important to note that the university admission process exists not only to select the candidates who are most likely to do well in school, but also to select a diverse body of capable students, giving rise to competent practitioners who can best serve the profession, the health care system, and the public $(8,19)$. In this context, the Brazilian Government has implemented in 2007 inclusion policies to promote equality of access to higher education and social diversity in public universities (20). Additional researches are essential to elucidate the impact of these changes in the selection process for university admission on student's performance.

Traditional studies of impact of gender on student performance found that men outperformance women, attributing possible reasons as: women's lowest sense of self-esteem, stereotype threat, differential speeds, aversion to risk taking, test bias, fear of success, test anxiety, and certain other personal characteristics (10). Recently, Fields et al. (11) investigated the impact of gender in student's performance among dental students and found that there were no significant differences. Authors related this result to no presence of true differences or low power of the sample to detect small differences. On other hand, our results show a trend to feminization of dentistry (Table 1) accompanied by better performance of women in academic assessments (Tables 1 and 4).

The relationship between student's performance and rate of class attendance and student workload hours is possible related to higher student involvement in academic experiences of learning, extension and research activities. Impact of the time elapsed from completion of high school until dental school admission in student's performance reinforces importance of previous educational experiences for success in university entrance immediately after high school and performance at graduation.

Assessment of student's performance plays a strategic role in pedagogical planning of educational institutes. The present study gives evidence about predictors of undergraduate student's performance and reinforces the need for curricular changes with improvement of the integration among courses. This critical evaluation proves significant information for dental schools currently engaged in, or about to embark upon, the task of planning and implementing strategies for training of general dentist according new required competencies.

Regional and cultural differences in educational principles may influence student's performance and suggest additional studies to corroborate the present findings. Additional longitudinal studies are needed to evaluate influence of student's performance in professional behavior and involvement.

\section{RESUMO}

A análise do desempenho acadêmico apresenta importante papel no planejamento educacional. O objetivo desse trabalho foi investigar fatores influenciadores do desempenho acadêmico de uma amostra retrospectiva constituída pelos estudantes de graduação ingressantes em uma Faculdade de Odontologia brasileira, em um período de 20 anos, entre 1984 e 2003 (n=1182). Variáveis demográficas e educacionais foram utilizadas para predizer o desempenho acadêmico global e por grupos de disciplinas. A análise de cluster (K-means) segmentou os estudantes em grupos de desempenho alto, moderado e baixo. Os clusters de desempenho global apresentaram validade externa, verificada pelo Teste do Qui-quadrado e ANOVA. O segmento com desempenho baixo apresentou menor número de estudantes nos clusters de desempenho global e por grupos de disciplinas, variando entre $11,8 \%$ (disciplinas clínicas) e 19,2\% (disciplinas do ciclo básico). O desempenho acadêmico por grupos de disciplinas foi superior em disciplinas profissionalizantes e clínicas $(p<0,001)$. Melhor desempenho acadêmico relacionou-se ao menor tempo entre ensino médio e ingresso na graduação, gênero feminino, melhor classificação no vestibular, maior freqüência no curso e carga horária do estudante em ensino, pesquisa e extensão $\left(\mathrm{R}^{2}=0,491\right)$. Nossos achados fornecem evidências sobre fatores preditores do desempenho acadêmico e reforçam a necessidade de reestruturação curricular focada na integração disciplinar.

\section{REFERENCES}

1. ADEA Commission on Change and Innovation in Dental Education. Competencies for the new dentist: (as approved by the 1997 house of delegates these competencies are being revised in 2006- 
07). J Dent Educ 2007;71:926-928.

2. Plasschaert AJ, Holbrook WP, Delap E, Martinez C, Walmsley AD. Association for Dental Education in Europe. Profile and competences for the European dentist. Eur J Dent Educ 2005;9:98-107.

3. Oliver R, Kersten H, Vinkka-Puhakka H, Alpasan G, Bearn D, Cema I, et al.. Curriculum structure: principles and strategy. Eur J Dent Educ 2008;12:74-84.

4. Baum BJ. Can biomedical science be made relevant in dental education? A North American perspective. Eur J Dent Educ 2003;7:49-55.

5. Crawford JM, Adami G, Johnson BR, Knight GW, Knoernschild $\mathrm{K}$, Obrez A, et al.. Curriculum restructuring at a north american dental school: rationale for change. J Dent Educ 2007;71:524-531.

6. Gaengler P, De Vries J, Akota L, Balciuniene I, Berthold P, Gajewska $\mathrm{M}$, et al.. Student selection and the influence of their clinical and academic environment on learning. J Dent Educ 2002;3:8-26.

7. Humphrey S, Skelton J, West K, MacPherson B. Toward better integration of biomedical science and clinical dentistry. J Dent Educ 2004;68:232-233.

8. Bergman AV, Susarla SM, Howell TH, Karimbux NY. Dental admission test scores and performance on NBDE Part I, revisited. J Dent Educ 2006;70:258-262.

9. Holmes DC, Doering JV, Spector M. Associations among predental credentials and measures of dental school achievement. J Dent Educ 2008;72:142-152.

10. Park SE, Da Silva JD, Barnes JL, Susarla SM, Howell TH. Predicting dental school performance based on prior dental experience and exposure. Eur J Dent Educ 2010;14:1-6.

11. Fields HW, Fields AM, Beck FM. The impact of gender on highstakes dental evaluations. J Dent Educ 2003;67:654-660.
12. Curtis DA, Lind SL, Brear S, Finzen FC. The correlation of student performance in preclinical and clinical prosthodontic assessments. J Dent Educ 2007;71:365-372.

13. Fugill M. Teaching and learning in dental student clinical practice. Eur J Dent Educ 2005;9:131-136.

14. Henzi D, Davis E, Jasinevicius R, Hendricson W. North American dental students' perspectives about their clinical education. J Dent Educ 2006;70:361-377.

15. American Dental Association Survey Center. 2003/2004 survey of predoctoral dental education: curriculum, volume 4. Chicago: American Dental Association, 2005.

16. McManus IC, Richards P. Audit of admissions to medical Schools. Br Med J 1998;296:1520-1521.

17. Lynch CD, McConnell RJ, Hannigan A. Dental school admissions in Ireland: can current selection criteria predict success? Eur J Dent Educ 2006;10:73-79.

18. Park SE, Susarla SM, Massey W. Do admissions data and NBDE Part I scores predict clinical performance among dental students? J Dent Educ 2006;70:518-524.

19. Kingsley K, Sewell J, Ditmyer M, O’Malley S, Galbraith GM. Creating an evidence-based admissions formula for a new dental school: University of Nevada, Las Vegas, School of Dental Medicine. J Dent Educ 2007;71:492-500.

20. Brazil. Decree $n^{\circ}$ 6.096, of April 24, 2007. It establishes the Program of Support for the Restructuring and Expansion of Federal Universities [in Portuguese]. Brasilia: Official Gazette, 2007.

Accepted March 2, 2010 